\title{
Aldosterone synthesis in the brain contributes to Dahl salt- sensitive rat hypertension
}

\author{
Elise P. Gomez-Sanchez ${ }^{1,2,3}$, Clara M. Gomez-Sanchez ${ }^{1}$, Maria Plonczynski ${ }^{1}$, and Celso E. \\ Gomez-Sanchez ${ }^{1,2}$ \\ ${ }^{1}$ Research Service, G. V. (Sonny) Montgomery VA Medical Center, University of Mississippi \\ Medical Center, Jackson, MS 39216, USA \\ ${ }^{2}$ Department of Medicine, Division of Endocrinology, University of Mississippi Medical Center, \\ Jackson, MS 39216, USA \\ ${ }^{3}$ Department of Pharmacology, University of Mississippi Medical Center, Jackson, MS 39216, \\ USA
}

\section{Abstract}

The enzymes required for aldosterone synthesis from cholesterol are expressed in rat and human brains. The hypertension of Dahl salt-sensitive (SS) rats is mitigated by the intracerebroventricular (I.c.). infusion of antagonists of the mineralocorticoid receptor (MR) and downstream effectors of mineralocorticoid action, as well as ablations of brain areas that also abrogate mineralocorticoidsalt excess hypertension in normotensive rats. We used real time RT-PCR to measure mRNA of aldosterone synthase and $11 \beta$-hydroxylase, the requisite enzymes for the last step in the synthesis of aldosterone and corticosterone, respectively, MR and the determinants of MR ligand specificity, $11 \beta$-hydroxysteroid dehydrogenase types 1 and $2(11 \beta$-HSD1\&2) and hexose-6-phosphate dehydrogenase (H6PDH). A combination of extraction and ELISA was used to measure aldosterone concentrations in tissue and urine of SS and Sprague-Dawley (SD) rats. Aldosterone synthase mRNA expression was higher in the brains and lower in the adrenal glands of SS compared with SD rats. The amounts of mRNA for MR, $11 \beta$-hydroxylase, $11 \beta$-HSD1\&2 and H6PD were similar. Aldosterone concentrations were greater in brains of SS than SD rats, yet, in keeping with the literature, the circulating and total aldosterone production of aldosterone in SS rats were not. The selective inhibitor of aldosterone synthase, FAD286, was infused I.c.v. or subcutaneously in a cross-over blood pressure study in hypertensive SS rats further challenged by a high-salt diet. The t.c.v. infusion of FAD286, at a dose that had no effect systemically, significantly and reversibly lowered blood pressure in SS rats. Aldosterone synthesis in brains of SS rats is greater than in SD rats and is important in the genesis of their salt-sensitive hypertension.

\begin{abstract}
Aldosterone acts through mineralocorticoid receptors (MR) in many cell types to modulate diverse physiological processes. Among these are electrolyte and fluid homeostasis, blood pressure, cardiovascular and renal function, tissue repair, activation of the central sympathetic nervous system and modulation of salt appetite (Gomez-Sanchez, 2004). In excess, mineralocorticoids produce hypertension. Ablation studies and selective infusions of antagonists and agonists implicate MR in circumventricular organs, especially those of the floor of the third ventricle, and the amygdala in the increase in central sympathetic drive,
\end{abstract}


release of arginine vasopressin and salt appetite, and the decrease in baroreceptor sensitivity, that contribute to the hypertension of mineralocorticoid-salt excess (Gomez-Sanchez, 1986; Janiak \& Brody, 1988; Gomez-Sanchez et al. 1990a; Janiak et al. 1990; Brody et al. 1991; Gomez-Sanchez \& Gomez-Sanchez, 1994, 2001). As expected, MR antagonists reduce hypertension and end-organ pathology in humans with hyperaldosteronism. However, they also reduce the blood pressure of some patients with normal plasma aldosterone and renin levels (Carey et al. 1972) and ameliorate heart and renal failure, even in patients with normal plasma aldosterone concentrations (London et al. 1977; reviewed by Pitt, 2004).

The Dahl salt-sensitive (SS) rat is a genetic model of salt-sensitive hypertension in which plasma renin and aldosterone concentrations are normal or low compared with control rats (Rapp et al. 1978; Baba et al. 1986) and are suppressed normally by high-salt diets (Pacha \& Pohlova, 1993). Notwithstanding, the hypertension in the SS rat resembles that of mineralocorticoid-salt excess in that manoeuvres that prevent this form of hypertension also prevent salt-induced hypertension in SS rats. These manoeuvres include ablation of the floor of the third ventricle (Goto et al. 1981) and the central sympathetic nervous system (Takeshita et al. 1979; Mark, 1991) and the inhibition of MR and MR action in the brain (Gomez-Sanchez et al. 1992; Gomez-Sanchez \& Gomez-Sanchez, 1994, 1995; Huang \& Leenen, 2005; Huang et al. 2005).

The MR has similar affinity for aldosterone and the main glucocorticoids, corticosterone and cortisol. Since glucocorticoids normally circulate at levels 100-1000 times that of aldosterone, there must be mechanisms to confer selectivity to the MR for aldosterone in mineralocorticoid target tissues. To date, the best known mechanism is the conversion of active corticosterone and cortisol to their inactive 11-dehydro metabolites by the enzyme $11 \beta$-hydroxysteroid dehydrogenase (11 $\beta$-HSD) type 2 within the aldosterone target cell (Stewart et al. 1987; Roland \& Funder, 1996). However, the presence of $11 \beta$-HSD2 has not been demonstrated in all tissues that are thought to be modulated by aldosterone, particularly in pathological conditions (Gomez-Sanchez \& Gomez-Sanchez, 1997). 11 $\beta$-Hydroxysteroid dehydrogenase type $2(11 \beta$-HSD2) is a reductase, in most physiological circumstances, that converts inactive 11-dehydro metabolites to active glucocorticoids in the presence of reduced nicotinamide adenine dinucleotide phosphate (NADPH). Hexose-6phosphodehydrogenase (H6PDH) is required to regenerate NADPH from $\mathrm{NADP}^{+}$in the endoplasmic reticulum (ER). In the absence of NADPH or H6PDH to regenerate it, $11 \beta$ HSD1 acts as a dehydrogenase (Atanasov et al. 2004; Banhegyi et al. 2004; Tomlinson et al. 2004). Both $11 \beta$-HSD enzymes are crucial for the regulation of intracellular concentrations of cortisol and corticosterone, thus activation of both the glucocorticoid and the mineralocorticoid receptors (Seckl \& Walker, 2001). Original reports that little or no significant amounts of $11 \beta$-HSD2 were expressed in the adult brain were due to its expression in a relatively small number of cells, making it difficult to detect (Yu et al. 2002; Geerling et al. 2006; Gomez-Sanchez et al. 2008). Geerling and co-workers have demonstrated the colocalization of the MR and $11 \beta$-HSD2 in discrete neurons of the nucleus tractus solitarii with immunohistochemistry (Geerling et al. 2006) and that more of such neurons are found in Dahl SS, compared with Dahl salt-resistant (SR), Sprague-Dawley (SD), Wistar and spontaneously hypertensive rats (Geerling et al. 2005). Mineralocorticoids have been assumed to act through the MR to regulate the expression and activity of components of the $\mathrm{Na}^{+}, \mathrm{K}^{+}$-ATPase and epithelial sodium channel subunits in the choroid plexus to modulate the volume and electrolyte content of cerebrospinal fluid (CSF; Davson \& Segal, 1996; Huang et al. 2004, 2006). However, this was not demonstrated by others (Takata et al. 1988). Moreover, the presence of $11 \beta$-HSD2 has not been confirmed in the choroid plexus, while $11 \beta$-HSD1, along with H6PDH, have, suggesting that glucocorticoids normally modulate CSF volume and electrolyte concentrations or that there is a different mechanism conferring aldosterone specificity to these MR (Gomez-Sanchez et al. 2009). 
In search of a mechanism other than $11 \beta$-HSD2 that would allow aldosterone to compete successfully with corticosterone for MR in target cells of the brain, we studied the possibility of the extra-adrenal synthesis of aldosterone in or near aldosterone target neurons. The requisite enzymes for aldosterone synthesis from cholesterol are expressed in the normal human and rat brains (Mellon, 1994; Stromstedt \& Waterman, 1995; GomezSanchez et al. 1996, 1997; MacKenzie et al. 2000; Yu et al. 2002), and low levels of aldosterone are synthesized in normal rat brain in vitro and in vivo (Gomez-Sanchez et al. 1996, 1997, 2005a). However, the amounts of extra-adrenal synthesis of aldosterone are so low in comparison with adrenal production that it has been impossible to measure reliably in the adrenal-intact subject and its physiological relevance is difficult to ascertain.

In support of a pathological role of excessive steroid production in the brain, we found that the intracerebroventricular (I.c.v.) infusion of the inhibitors of steroid synthesis, trilostane and 19-ethynyl-deoxycorticosterone, prevented the increase in blood pressure of SS rats upon salt challenge (Gomez-Sanchez et al. 1997, 2005b). However, while suggestive, neither inhibitor is selective for aldosterone synthase (AS); the reduction in blood pressure could have resulted from any combination of a reduction in Deoxycorticosterone (DOC), aldosterone or corticosterone. Until recently, there has been no evidence that aldosterone synthesis in the brains of the SS rats is greater than in normotensive rats, primarily due to the difficulty of measuring such an increase when steroidogensis is limited to a select few cells in the brain (MacKenzie et al. 2002;Gomez-Sanchez et al. 2005a; Huang et al. 2009b).

In an attempt to elucidate why the hypertension of the SS rat appears to be driven by activation of MR in the brain despite low or normal levels of circulating aldosterone, we present new information about the expression of AS, the MR and the enzymes required for MR selectivity for aldosterone in the brains of SS compared with normotensive rats, as well as the effect of a recently developed selective AS inhibitor, FAD286 (Fiebeler et al. 2005), on established hypertension in the Dahl SS strain.

\section{Methods}

\section{Animal model}

Sprague-Dawley (SD) and Dahl salt-sensitive (SS) rats were housed at the Jackson VA American Association for the Accreditation of Laboratory Animal Care accredited animal facility under the care of an American College of Laboratory Animal Medicine boarded veterinarian; all protocols were approved by the Jackson VA Institutional Animal Care and Use Committee. The inbred SS rats have been maintained in our laboratory as a closed colony since breeding pairs were provided by Dr John Rapp, Medical College of Ohio, in 1984. Rats of the same sex born within 7 days of each other were used in each experiment. Littermates were randomly assigned to all groups, with no more than two littermates in the same group. Like both male and female SD rats receiving an excess of mineralocorticoids (Gomez-Sanchez \& Gomez-Sanchez, 1999), male and female SS rats consuming a standard rat chow $(0.3-0.4 \% \mathrm{NaCl})$ and tap water predictably develop hypertension with time. The rate of blood pressure rise is exacerbated by high sodium consumption (Gomez-Sanchez et al. 2005b). Rats were raised on tap water and a standard maintenance rodent chow with $0.4 \% \mathrm{NaCl}$ (Teklad 8640; Harlan- Teklad, Indianapolis, IN, USA) ad libitum and salt challenged by substituting $0.9 \%$ saline for water. Unlike our experience with high-salt chows, young animals drinking physiological saline continue to gain weight at a normal rate.

\section{Tissue samples}

To obtain blood and brain samples, rats were anaesthetized with isoflurane delivered in oxygen with a standard inhalant anesthetic machine, a blood sample taken by cardiac 
puncture within 2 min of the rat being picked up, the thorax opened, the vena cava cut, and the rat perfused with heparinized saline through the left ventricle to remove blood. Brains were immediately frozen whole or cooled in iced saline and divided into brainstem, cerebellum, cortex, hippocampus and hypothalamus before freezing.

\section{Real time RT-PCR}

Real time RT-PCR was used to measure mRNA for CYP11B2 (coding for AS), CYP11B1 (for 11 $\beta$-hydroxylase), 11 $\beta$-hydroxysteroid dehydrogenase types 1 and 2 and hexose-6phosphate dehydrogenase (H6PDH), in different areas of the brain using primers described by us (Gomez-Sanchez et al. 2003, 2006, 2008). Brains and adrenal glands from four SS rats and six SD rats of the same age, but different dams, were used for Figs 1 and 2.

\section{Aldosterone assays}

Aldosterone assays were done as described by researchers in our laboratory (GomezSanchez et al. 2005a). Plasma ( $0.5 \mathrm{ml})$ was extracted in $5 \mathrm{ml}$ dichloromethane, reconstituted in 200-250 $\mu$ l of ELISA buffer, and $50 \mu \mathrm{l}$ used to measure aldosterone by ELISA using a selective monoclonal antibody produced by us (Gomez-Sanchez et al. 1987b) and validated by several other laboratories (Abayasekara et al. 1993; Yu et al. 2008; Ye et al. 2009). One millilitre of urine was extracted in $5 \mathrm{ml}$ dichloromethane, reconstituted in $330 \mu \mathrm{l}$ of ELISA buffer, and $50 \mu \mathrm{l}$ used to measure aldosterone by ELISA. All assays were done in triplicate and included blanks. The aldosterone concentration in brain, plasma and urine was measured as previously described (Gomez-Sanchez et al. 2005a). Aldosterone concentrations were expressed as picograms per gram of tissue, picograms per millilitre for plasma and picograms per milligram of creatinine for urine. For the comparison of SS and SD brain parts, each sample size $(n)$ comprised the pooled brain parts from three animals, $n=8$ (total 24 rats). Pairs of 11-week-old female rats were placed in metabolism cages for 3 days of acclimation before the beginning of three consecutive $24 \mathrm{~h}$ urine collections; $n=9$ (total 18 rats) for SS and $n=8$ (total 16) for SD rats. Rats are social creatures. The advantage of using female rather than male rats is that the females are small enough to fit comfortably in a metabolism cage, reducing the stress of isolation and the time until stable daily corticosterone output is obtained (Gomez-Sanchez et al. 1987a; Gomez-Sanchez \& GomezSanchez, 1988, 1991a,b). Aldosterone excretion by female and male rats once they have become accustomed to the metabolism cage is not different (Gomez-Sanchez \& GomezSanchez, 1988). Potential differences due to oestrus cycle between groups were mitigated by spanning the length of the oestrus cycle.

\section{Blood pressure studies}

Systolic blood pressure was measured by tail-cuff plethysmography (IITC Life Science Inc., Woodland Hills, CA, USA) in well-trained unheated male rats between 08.00 and $12.00 \mathrm{~h}$, two or three times per week in their cage room, a designated quiet zone with no other animals, maintained at $25 \pm 1^{\circ} \mathrm{C}$. To minimize stress, no animal was restrained for more than $10 \mathrm{~min}$ at a time. If a rat did not settle within 2-3 min after entering the tube, it was provided home cage time before trying to measure the pressure again (Gomez-Sanchez, 1994). The time required for the rat to settle and relax its tail was noted. Body weight was recorded after each blood pressure measurement. Intracerebroventricular (..c.v.) cannulae and mini-osmotic pumps (Alzet 2004, DURECT Corp., Cupertino, CA, USA) were placed under isoflurane anaesthesia with buprenorphine (0.03-0.05 $\mathrm{mg} \mathrm{kg}^{-1} \mathrm{sc}$, intra-operatively and q8-12 hr prn; Bedford Laboratories, Bedford, OH, USA) for postoperative analgesia as described by us (Gomez-Sanchez, 1986; Gomez-Sanchez et al. 1990a; Gomez-Sanchez, 1994; GomezSanchez \& Gomez-Sanchez, 1995). All implants and the solutions were sterile. Saline (0.9\% $\mathrm{NaCl}$ ) was substituted for water the day after the first pumps were placed. A selective inhibitor of aldosterone synthase, FAD286, was received as a gift from the Novartis 
Institutes for BioMedical Research in 2005. We extrapolated from oral doses used in the first published studies of FAD286 inhibitory activity to calculate the doses for infusion (Fiebeler et al. 2005). FAD286 is not very soluble in an aqueous solution; it was first dissolved in distilled propylene glycol, then diluted in physiological saline to make a $20 \%$ propylene glycol solution for infusions. Control animals received 20\% propylene glycol. There were four groups of SS males: (1) $20 \%$ propylene glycol vehicle ı...v. $(n=8)$; (2) $30 \mu \mathrm{g}$ $\mathrm{h}^{-1}$ FAD286 i.c.v. $(n=9)$; (3) $100 \mu \mathrm{g} \mathrm{h}^{-1}$ FAD286 i.c.v. $(n=8)$; and (4) vehicle i.c.v. and $100 \mu \mathrm{g}$ $\mathrm{h}^{-1}$ FAD286 s.c. After training and obtaining baseline blood pressures, ..... cannulae were placed, and infusions and high-salt consumption started at 15 weeks of age. Three weeks later, the pumps and treatments were changed so that groups 1 (vehicle) and $2\left(30 \mu \mathrm{g} \mathrm{h}^{-1}\right.$ FAD286 i.c.v.) remained the same, but group 3 received vehicle i.c.v., instead of $100 \mu \mathrm{g} \mathrm{h}^{-1}$ FAD286 I...v., and group 4 received $100 \mu \mathrm{g} \mathrm{h}^{-1}$ FAD286 i.c.v., instead of vehicle I.c.v. and 100 $\mu \mathrm{g} \mathrm{h}^{-1}$ FAD286 s.c. The elevated plus maze was designed to assess anxiety, but also allows observation of gross ataxia, tremors or other motor abnormalities (Wright et al. 1992; Bitran et al. 1998). The rats were tested on the elevated + maze as described by us (GomezSanchez et al. 2005b) once, near the end of the third week, to avoid training bias. Proper positioning of the cannulae was ascertained by dye infusion at necropsy. Rats were anaesthetized with isoflurane, a blood sample taken by cardiac puncture within $2 \mathrm{~min}$ of the rat being picked up, the thorax opened, the vena cava cut, and the rat perfused with heparinized saline through the left ventricle to remove blood of the beating heart, and the kidneys, adrenals and heart removed for weighing.

\section{Statistics}

Differences between two groups were evaluated by Student's paired $t$ test; more than two groups were evaluated by analysis of variance for repeated measures, followed by a Tukey contrast where appropriate (STATISTICA 6.0; StatSoft package, StatSoft, Inc., Tulsa, OK, USA). Results are expressed as the means \pm s....

\section{Results}

Results of the quantitative RT-PCR are shown in Figs 1 and 2. The mean value for the ratio of mRNA of interest/GAPDH for the cerebellum of SD rats was arbitrarily assigned the value of 1 and used to compare the mRNA levels for the rest of the samples. Figure $1 \mathrm{~A}$ and B compares the amount of mRNA for CYP11B2 and CYP11B1, encoding the AS and $11 \beta$ hydroxylase enzymes, respectively, in different brain regions and the adrenal glands of SS and SD rats. Messenger RNA for AS was clearly expressed in all of the brain parts; however, maximal expression of AS in the brain was less than 1/1000 of that in the adrenal gland. Messenger RNA for AS tended to be greater in SS than in SD rats in all brain parts and was significantly greater $(P<0.05)$ in the brainstem, hippocampus and cortex.

Messenger RNA for the $11 \beta$-hydroxylase in the brain parts was similar in the SS and SD brainstem and hippocampus, and less in the SS rat hypothalamus and cerebellum $(P<0.01)$ and cortex $(P<0.05)$. The patterns of AS and $11 \beta$-hydroxylase expression in the brain differed. In both strains, the amount of mRNA for AS was greatest in the brainstem and hypothalamus, while mRNA for $11 \beta$-hydroxylase was greatest in the cortex. Expression of AS mRNA was significantly less $(P<0.05)$ and $11 \beta$-hydroxylase mRNA greater $(P<0.01)$ in the adrenals of the SS compared with the SD rats.

Amounts of mRNA for MR, 11 $\beta$-HSD1, $11 \beta$-HSD2 and H6PDH were similar in the brains and adrenal glands of both strains (Fig. 2). As expected, the greatest MR mRNA expression was in the hippocampus. Expression of $11 \beta$-HSD2 was greatest in the hypothalamus of both strains; however, it was two orders of magnitude less than its expression in the adrenal gland. 
Figure $3 \mathrm{~A}$ represents the $24 \mathrm{~h}$ urinary excretion of aldosterone expressed as picograms aldosterone per milligram of creatinine per rat, averaged over 3 days, from nine pairs of SS and eight pairs of SD female rats in each metabolism cage. The rats were acclimated for 3 days before the collections were started. Daily aldosterone excretion, reflecting total daily production, was significantly greater in SD than SS rats $(P<0.01)$.

Figure $3 \mathrm{~B}$ is a comparison of the aldosterone content in the brainstem, hypothalamus and cerebellum of 3-month-old male SS and SD rats. For these measurements, $n=8$, with each $n$ comprising tissue pooled from three rats. Aldosterone in the hypothalamus of the SS rat was significantly greater than that of the SD rat $(P<0.05)$.

Figure 4 shows the blood pressure results of a cross-over study in salt-challenged male SS rats receiving continuous infusions of vehicle i.c.v., FAD286 i.c.v. or FAD286 s.c. Weight gain did not differ between groups and was as expected for male SS rats between the ages of 3 and 5 months old, increasing from $374 \pm 19$ to $408 \pm 23 \mathrm{~g}$. There were no signs of neurotoxicity or differences in behaviour or motor ability between groups. As expected at this age, all rats were hypertensive before the beginning of the experiment. Within 13 days after starting the high salt intake, the blood pressure of the SS rats receiving the i.c.v. infusion of vehicle (dotted line and filled circles) was consistently and significantly greater $(P<0.05)$ than their pressures recorded on three different days prior to the start of the experiment. The blood pressures of the rats receiving i.c. vehicle $+100 \mu \mathrm{g} \mathrm{h}^{-1}$ FAD286 s.c., the largest dose of FAD286 (open inverted triangles) were significantly greater than their pre-salt challenge pressures within 8 days $(P<0.05)$ and remained significantly elevated, at the same level as those of the rats receiving vehicle i.c.v. alone, during the first 3 weeks, demonstrating that the systemic infusion of this dose of FAD286 did not lower the salt-sensitive increment in blood pressure. The blood pressures of the rats receiving the infusion of the lower dose, $30 \mu \mathrm{g} \mathrm{h}^{-1}$ FAD286 I.c.v. (dotted line and open circles), initially increased significantly compared with their initial blood pressures, then returned to their baseline by day 17 and remained at this level for the duration of the experiment. The blood pressures of the rats receiving $100 \mu \mathrm{g} \mathrm{h}^{-1}$ FAD286 i.c.v. (filled inverted triangles) did not increase above their baseline for the first 3

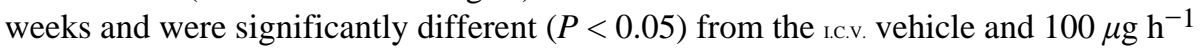
FAD286 s.c. groups by day 8 . The pumps were changed at 22 days. Rats in group 3, receiving $100 \mu \mathrm{g}$ FAD286 i.c. from the beginning (filled inverted triangles), maintained their pre-salt challenge blood pressure until 5 days after their FAD286 I.c.v. was replaced with vehicle ı.c.v., by which time their blood pressure had increased to a level similar to that of rats that never received FAD286 I.c.v. Five days after the I.c.v. pumps of the rats who had initially received I.c.v. vehicle $+100 \mu \mathrm{g} \mathrm{h}^{-1}$ FAD286 s.c. were changed to deliver $100 \mu \mathrm{g} \mathrm{h}^{-1}$ FAD286 I.c.v. (the s.c. infusions were discontinued), their blood pressures decreased significantly to levels similar to their pre-salt challenge pressures and to those of the other rats receiving FAD286 i.c.. Blood levels of aldosterone at the time that the experiment was terminated, 24 days after the pump change, did not differ between groups (data not shown).

\section{Discussion}

Dahl SS rats become hypertensive with age on a standard rat chow; therefore, our measurements, except those of the effect of FAD286 on the blood pressure, were made in animals on a standard diet. While mRNA for AS in the brains of SS rats was greater than in the brains of SD rats, the pattern of AS mRNA distribution in the brains of the normotensive $\mathrm{SD}$ rats is concordant with the hypothesis that the synthesis of aldosterone in the brain serves a regulatory function in normal cardiovascular physiology. Of the brain parts studied, the greatest AS expression in both the normotensive SD and the SS rats was in the brainstem and hypothalamus, areas shown by ablation and pharmacological studies to be important for haemodynamic regulation by mineralocorticoids. The levels of aldosterone in the brainstem 
and cerebellum of both the SS and the SD rats are comparable to those found in the whole brains of SD and Wistar rats on a standard salt diet (Gomez-Sanchez et al. 2005a), while the content in the hypothalamus of the SS and SD rats was significantly greater, with that of the SS greater than the SD. The infusion of FAD286 in younger non-hypertensive SS rats prevented the rise in blood pressure upon salt challenge (Huang et al. 2009b) and reversibly prevented the further increase in blood pressure in older hypertensive SS rats in this study. The relative amounts of mRNA for the $11 \beta$-hydroxylase enzyme, responsible for the production of corticosterone, tended to be the mirror image of those for AS in both SS and $\mathrm{SD}$ rats; the highest expression being in the cortex. While mRNA does not always correlate with protein or protein with active enzyme (Gomez-Sanchez et al. 2003), these data suggest that the extra-adrenal synthesis of aldosterone in the brainstem and hypothalamus and of corticosterone in the cortex may allow for ligands of the MR and glucocorticoid receptor (GR) to be regulated independently of the systemic renin-angiotensin-aldosterone system (RAAS) and hypothalamic-pituitary-adrenal axis (HPA). Unfortunately, owing to its limited expression, at this time no one has reported a reliable way to quantify AS protein in the brain. Immunohistochemistry using our antibody demonstrates that AS protein is selectively expressed in pyramidal neurons of the hippocampus and Purkinje cells of the cerebellum of normotensive rats (MacKenzie et al. 2000, 2002), and we have demonstrated limited staining in the paraventricular nucleus and brainstem nuclei (E.P. Gomez-Sanchez, unpublished observations).

The results of activation of MR in the brain, unlike those in the kidney, differ depending on whether the ligand is a mineralocorticoid or glucocorticoid. Hippocampal MR are occupied primarily by circulating levels of corticosterone, and replacement with aldosterone in the adrenalectomized rat does not restore hippocampal function (De Kloet et al. 1983, 2000; Reul \& De Kloet, 1985; Gomez-Sanchez et al. 1990b). The biggest difference in AS mRNA expression between the SS and SD rats was in the hippocampus. The SS rat is a comparatively placid rat, which is easily handled and appears to learn, remember and adapt to novel situations easily. The rudimentary tests performed in the FAD286 infusion studies detected no overt changes in behaviour or cognition produced by the i.c.v. infusion of the inhibitor. Extrapolating from a recent paper comparing aldosterone content in the hypothalamus and hippocampus after i.c.v. infusion (Huang et al. 2009b), FAD286 probably does not reach the hippocampus in effective doses. The implications of extra AS mRNA in the hippocampus have yet to be studied. The significance of immunohistochemical evidence of AS in hippocampal neurons in normotensive rat strains and greater AS mRNA in the hippocampus and cortex of the SS compared with the SD rat awaits further studies.

The Dahl SS rat has often been compared with the Dahl SR rat. However, just as the SS rat was bred for salt-sensitive hypertension, the SR rat was bred for resistance. Analysis of the sequence of the AS gene indicates that the CYP11B2 of the SS rat is different from that of the SR rat and the same as several different normotensive rat strains; the SR is the outlier (Cicila et al. 1993; Ginn et al. 1993). The CYP11B2 gene fixed by inbreeding in the SR genome is more efficient than the SS gene (Cover et al. 1995; Lloyd-MacGilp et al. 2002). In addition, many physiological factors have been implicated in the hypertension of the SS rat. Similarly, the SR rat may have an unknown number of genetic factors that produce its resistance. Therefore, it was important to verify the differences in brain steroidogenesis between the SS rat and a normotensive rat in addition to the SR rat (Huang et al. 2009b).

As expected from the literature (Rapp et al. 1978; Baba et al. 1986, Pacha \& Pohlova, 1993), total $24 \mathrm{~h}$ aldosterone synthesis in SS rats was lower than that of SD rats. Aldosterone levels in blood increase with activity producing orthostatic changes that stimulate angiotensin II, the most important regulator of aldosterone synthesis, and are influenced by the circadian rhythm of adrenocorticotrophic hormone and increased by acute stress. Therefore, 
measurement of aldosterone excreted in the urine over $24 \mathrm{~h}$ in properly acclimated animals is a more accurate indication of basal aldosterone synthesis than momentary blood levels. Concordant with significantly less adrenal AS mRNA, $24 \mathrm{~h}$ aldosterone excretion in the urine, normalized to creatinine excretion, was significantly less in SS compared with SD rats, but aldosterone concentration in their brains was greater. Most of the aldosterone in the brains of normotensive rats (SD and Wistar rats) is derived from the circulation (GomezSanchez et al. 2004, 2005a). The only known mechanism to sequester aldosterone is by binding by the MR (Tsutamoto et al. 2000, 2003), and expression of MR mRNA is not increased in the brains of SS compared with SD rats. The distribution and relative amounts of MR mRNA in the different brain parts in our studies correlate well with autoradiographic studies (Birmingham et al. 1979; Reul \& De Kloet, 1985). If the increase in aldosterone content were due to binding of circulating steroid to MR, one would expect that the hippocampus would have a greater concentration than the hypothalamus. In a comparison of SS and SR rats consuming a normal-salt diet, aldosterone concentrations in the hippocampus and hypothalamus of were similar, and slightly lower than the plasma levels, in the $500 \mathrm{pg}$ $\mathrm{ml}^{-1}$ range (Huang et al. 2009b). Leenen and Huang's laboratories have reported significant increments in the aldosterone content of the hypothalamus, but not hippocampus, in a rat model hypertension due to the intracerebroventricular infusion of hypernatraemic artificial CSF (Huang et al. 2008) and that aldosterone increases in the hippocampus to a greater extent than in the hypothalamus in a model of myocardial infarction (Huang et al. 2009a). The aldosterone concentration in the plasma and brains in these reports were in the 300-400 $\mathrm{pg} \mathrm{ml}^{-1}$ and 300-700 $\mathrm{pg} \mathrm{g}^{-1}$ ranges, respectively; values that indicate considerable acute stress, increasing circulating aldosterone levels by at least an order of magnitude at the time of sample collection (Gomez-Sanchez et al. 1976). Similar studies of brains at basal nonstressed aldosterone levels will be of great interest because circulating stress levels of aldosterone may mask basal levels in the different brain parts (Gomez-Sanchez et al. 2005a).

Similarly, the regulation of aldosterone production in the brain is still not understood in either normotensive or SS rats because most of the brain aldosterone derives from the circulation and the amount of aldosterone produced by the adrenal is huge compared with that of the brain. Blood levels of aldosterone were found to be similarly suppressed by a high-salt diet in SS, Wistar and SR rats; however, circulating aldosterone levels in the SS rat were increased less by a low-salt diet compared with the Wistar and SR rats (Pacha \& Pohlova, 1993). We have confirmed reports that circulating aldosterone is stimulated and suppressed as expected by low- and high-salt diets, respectively, in the SD and SS rat (E.P. Gomez-Sanchez, unpublished observations). A high-salt diet was recently reported to have significantly decreased aldosterone in the hypothalamus and hippocampus of SR rats, but greatly increased aldosterone in the hypothalamus of SS rats without altering aldosterone in the hippocampus (Huang et al. 2009b). Plasma aldosterone was not lowered by the high-salt diet in this study; however, the levels were in the $600 \mathrm{pg} \mathrm{ml}^{-1}$ range, indicating acute stress, which may have masked suppression. Notwithstanding, this difference between the hypothalamic aldosterone content between the SS and SR rat is very interesting in light of data published 35 years ago, which demonstrated that the mineralocorticoid binding capacity of the hypothalamus of rats resistant to DOCA-salt hypertension is significantly less than that of normal rats (Lassman \& Mulrow, 1974).

Over 50 years of study demonstrate that the pathology in the Dahl SS rat is complex and probably involves several genes and systems. Our present study and that of Huang et al. (2009b) demonstrate that aldosterone synthesis in the brain, though very low, is greater in the SS rat compared with the SD rat, and this increase is a component of their salt-sensitive hypertension. While the requisite enzymes for aldosterone synthesis from cholesterol are expressed in the human brain (Yu et al. 2002), the relevance of extra-adrenal synthesis of aldosterone in the brain in normotensive rats in different physiological conditions and in 
other species has yet to be studied. Such studies will require the development of even more sensitive methods to measure minute changes in aldosterone concentration against the backdrop of normal circulating adrenal steroids.

\section{Acknowledgments}

This work was supported by Medical Research funds from the Department of Veterans Affairs and NIH grants HL27255 and HL75321.

\section{References}

Abayasekara DR, Onyezili NI, Whitehouse BJ, Laird SM, Vinson GP. Effects of chronic corticotrophin treatment on aldosterone metabolism in the rat. J Endocrinol. 1993; 137:445-455. [PubMed: 8396622]

Atanasov AG, Nashev LG, Schweizer RA, Frick C, Odermatt A. Hexose-6-phosphate dehydrogenase determines the reaction direction of $11 \beta$-hydroxysteroid dehydrogenase type 1 as an oxoreductase. FEBS Lett. 2004; 571:129-133. [PubMed: 15280030]

Baba K, Mulrow PJ, Franco-Saenz R, Rapp JP. Suppression of adrenal renin in Dahl salt-sensitive rats. Hypertension. 1986; 8:1149-1153. [PubMed: 3539795]

Banhegyi G, Benedetti A, Fulceri R, Senesi S. Cooperativity between $11 \beta$-hydroxysteroid dehydrogenase type 1 and hexose-6-phosphate dehydrogenase in the lumen of the endoplasmic reticulum. J Biol Chem. 2004; 279:27017-27021. [PubMed: 15090536]

Birmingham MD, Stumpf WE, Sar M. Nuclear Iocalization of aldosterone in rat brain cells assessed by autoradiography. Experientia. 1979; 35:1240-1241. [PubMed: 488294]

Bitran D, Shiekh M, Dowd JA, Dugan MM, Renda P. Corticosterone is permissive to the anxiolytic effect that results from the blockade of hippocampal mineralocorticoid receptors. Pharmacol Biochem Behav. 1998; 60:879-887. [PubMed: 9700972]

Brody MJ, Varner KJ, Vasquez EC, Lewis SJ. Central nervous system and the pathogenesis of hypertension. Sites and mechanisms. Hypertension. 1991; 18:III7-III12. [PubMed: 1937689]

Carey RM, Douglas JG, Schweikert JR, Liddle GW. The syndrome of essential hypertension and suppressed plasma renin activity. Normalization of blood pressure with spironolactone. Arch Intern Med. 1972; 130:849-854. [PubMed: 5082464]

Cicila GT, Rapp JP, Wang JM, St Lezin E, Ng SC, Kurtz TW. Linkage of $11 \beta$-hydroxylase mutations with altered steroid biosynthesis and blood pressure in the Dahl rat. Nat Genet. 1993; 3:346-353. [PubMed: 7981756]

Cover CM, Wang J, St Lezin E, Kurtz TW, Mellon SH. Molecular variants in the P450c11AS gene as determinants of aldosterone synthase activity in the Dahl rat model of hypertension. J Biol Chem. 1995; 270:16555-16560. [PubMed: 7622461]

Davson, H.; Segal, MB. Physiology of the CSF and Blood-Brain Barriers. CRC Press; Boca Ratan, FL, USA: 1996.

De Kloet ER, Van Acker SA, Sibug RM, Oitzl MS, Meijer OC, Rahmouni K, de Jong W. Brain mineralocorticoid receptors and centrally regulated functions. Kidney Int. 2000; 57:1329-1336. [PubMed: 10760063]

De Kloet ER, Versteeg DHG, Kovacs GL. Aldosterone blocks the response to corticosterone in the raphe-hippocampal serotonin system. Brain Res. 1983; 264:323-327. [PubMed: 6850304]

Fiebeler A, Nussberger J, Shagdarsuren E, Rong S, Hilfenhaus G, Al-Saadi N, Dechend R, Wellner M, Meiners S, Maser-Gluth C, Jeng AY, Webb RL, Luft FC, Muller DN. Aldosterone synthase inhibitor ameliorates angiotensin II-induced organ damage. Circulation. 2005; 111:3087-3094. [PubMed: 15939810]

Geerling JC, Kawata M, Loewy AD. Aldosterone-sensitive neurons in the rat central nervous system. J Comp Neurol. 2006; 494:515-527. [PubMed: 16320254]

Geerling JC, Sequeira SM, Loewy AD. Increased number of aldosterone-sensitive NTS neurons in Dahl salt-sensitive rats. Brain Res. 2005; 1065:142-146. [PubMed: 16316636] 
Ginn DI, Baptista CA, Alam KY, Deng AY, Cicila GT, Margolius HS, Rapp JP. Estimate of the genetic divergence between inbred Dahl salt-sensitive and salt-resistant rats. J Hypertens. 1993; 11:477-481. [PubMed: 8099934]

Gomez-Sanchez CE, Bataillard A, Vincent M, Sassard J. Urinary mineralocorticoids in genetically hypertensive rats of the Lyon strain. J Hypertension. 1987a; 5(Suppl 5):S227-S229.

Gomez-Sanchez CE, de Rodriguez AF, Romero DG, Estess J, Warden MP, Gomez-Sanchez MT, Gomez-Sanchez EP. Development of a panel of monoclonal antibodies against the mineralocorticoid receptor. Endocrinology. 2006; 147:1343-1348. [PubMed: 16293659]

Gomez-Sanchez CE, Foecking MF, Ferris MW, Chavarri MR, Uribe L, Gomez-Sanchez EP. The production of monoclonal antibodies against aldosterone. Steroids. 1987b; 49:581-587. [PubMed: 3453564]

Gomez-Sanchez CE, Gomez-Sanchez EP. Role of central mineralocorticoid receptors in cardiovascular disease. Curr Hypertens Rep. 2001; 3:263-269. [PubMed: 11353578]

Gomez-Sanchez CE, Holland OB, Higgins JR, Kem DC, Kaplan NM. Circadian rhythms of serum renin activity and serum corticosterone, prolactin, and aldosterone concentrations in the rat during normal and low sodium diet. Endocrinology. 1976; 99:567-572. [PubMed: 954653]

Gomez-Sanchez CE, Zhou MY, Cozza EN, Morita H, Eddleman FC, Gomez-Sanchez EP. Corticosteroid synthesis in the central nervous system. Endocr Res. 1996; 22:463-470. [PubMed: 8969897]

Gomez-Sanchez CE, Zhou MY, Cozza EN, Morita H, Foecking MF, Gomez-Sanchez EP. Aldosterone biosynthesis in the rat brain. Endocrinology. 1997; 138:3369-3373. [PubMed: 9231789]

Gomez-Sanchez EP. Intracerebroventricular infusion of aldosterone induces hypertension in rats. Endocrinology. 1986; 118:819-823. [PubMed: 3943493]

Gomez-Sanchez EP. Hypertension and the mineralocorticoid receptor in the brain. Ann NY Acad Sci. 1994; 746:415-417. [PubMed: 7825903]

Gomez-Sanchez EP. Brain mineralocorticoid receptors: orchestrators of hypertension and end-organ disease. Curr Opin Nephrol Hypertens. 2004; 13:191-196. [PubMed: 15202613]

Gomez-Sanchez EP, Ahmad N, Romero DG, Gomez-Sanchez CE. Origin of aldosterone in the rat heart. Endocrinology. 2004; 145:4796-4802. [PubMed: 15308609]

Gomez-Sanchez EP, Ahmad N, Romero DG, Gomez-Sanchez CE. Is aldosterone synthesized within the rat brain? Am J Physiol Endocrinol Metab. 2005a; 288:E342-E346. [PubMed: 15479953]

Gomez-Sanchez EP, Fort C, Thwaites D. Central mineralocorticoid receptor antagonism blocks hypertension in Dahl S/JR rats. Am J Physiol Endocrinol Metab. 1992; 262:E96-E99.

Gomez-Sanchez EP, Fort CM, Gomez-Sanchez CE. Intracerebroventricular infusion of RU28318 blocks aldosterone-salt hypertension. Am J Physiol Endocrinol Metab. 1990a; 258:E482-E484.

Gomez-Sanchez EP, Ganjam V, Chen YJ, Liu Y, Zhou MY, Toroslu C, Romero DG, Hughson MD, de Rodriguez A, Gomez-Sanchez CE. Regulation of $11 \beta$-hydroxysteroid dehydrogenase enzymes in the rat kidney by estradiol. Am J Physiol Endocrinol Metab. 2003; 285:E272-E279. [PubMed: 12700160]

Gomez-Sanchez EP, Gomez-Sanchez CE. 19-Nordeoxycorticosterone excretion in male and female inbred salt-sensitive (S/JR) and salt-resistant (R/JR) rats. Endocrinology. 1988; 122:1110-1113. [PubMed: 3342746]

Gomez-Sanchez EP, Gomez-Sanchez CE. 19-Nordeoxycorticosterone, aldosterone and corticosterone excretion in sequential urine samples of male and female rats. Steroids. 1991a; 56:451-454. [PubMed: 1788863]

Gomez-Sanchez EP, Gomez-Sanchez CE. The effect of gonadectomy and aromatase inhibition on the excretion of 19-nordeoxycorticosterone in rats. J Steroid Biochem Mol Biol. 1991b; 39:185-188. [PubMed: 1888677]

Gomez-Sanchez EP, Gomez-Sanchez CE. Effect of central amiloride infusion on mineralocorticoid hypertension. Am J Physiol Endocrinol Metab. 1994; 267:E754-E758.

Gomez-Sanchez EP, Gomez-Sanchez CE. The effect of the central infusion of benzamil on Dahl S rat hypertension. Am J Physiol Heart Circ Physiol. 1995; 269:H1044-H1047.

Gomez-Sanchez EP, Gomez-Sanchez CE. Editorial: First there was one, then two... why more $11 \beta$ hydroxysteroid dehydrogenases? Endocrinology. 1997; 138:5087-5088. [PubMed: 9389486] 
Gomez-Sanchez EP, Gomez-Sanchez CE. Maternal hypertension and progeny blood pressure: role of aldosterone and 11 $\beta$-HSD. Hypertension. 1999; 33:1369-1373. [PubMed: 10373218]

Gomez-Sanchez EP, Gomez-Sanchez MT, de Rodriguez AF, Romero DG, Warden MP, Plonczynski MW, Gomez-Sanchez CE. Immunohistochemical demonstration of the mineralocorticoid receptor, $11 \beta$-hydroxysteroid dehydrogenase- 1 and -2 , and hexose-6-phosphate dehydrogenase in rat ovary. J Histochem Cytochem. 2009; 57:633-641. [PubMed: 19255253]

Gomez-Sanchez EP, Romero DG, de Rodriguez AF, Warden MP, Krozowski Z, Gomez-Sanchez CE. Hexose-6-phosphate dehydrogenase and $11 \beta$-hydroxysteroid dehydrogenase-1 tissue distribution in the rat. Endocrinology. 2008; 149:525-533. [PubMed: 18039793]

Gomez-Sanchez EP, Samuel J, Vergara G, Ahmad N. Effect of $3 \beta$-hydroxysteroid dehydrogenase inhibition by trilostane on blood pressure in the Dahl salt-sensitive rat. Am J Physiol Regul Integr Comp Physiol. 2005b; 288:R389-R393. [PubMed: 15458970]

Gomez-Sanchez EP, Venkataraman MT, Thwaites D. ICV infusion of corticosterone antagonizes ICValdosterone hypertension. Am J Physiol Endocrinol Metab. 1990b; 258:E649-E653.

Goto A, Ikeda T, Tobian L, Iwai J, Johnson MA. Brain lesions in the paraventricular nuclei and catecholaminergic neurons minimize salt hypertension in Dahl salt-sensitive rats. Clin Sci. 1981; 61:53s-55s. [PubMed: 7318357]

Huang BS, Cheung WJ, Wang H, Tan J, White RA, Leenen FH. Activation of brain renin-angiotensinaldosterone system by central sodium in Wistar rats. Am J Physiol Heart Circ Physiol. 2006; 291:H1109-H1117. [PubMed: 16603700]

Huang BS, Leenen FH. Blockade of brain mineralocorticoid receptors or $\mathrm{Na}^{+}$channels prevents sympathetic hyperactivity and improves cardiac function in rats post-MI. Am J Physiol Heart Circ Physiol. 2005; 288:H2491-H2497. [PubMed: 15615845]

Huang BS, Van Vliet BN, Leenen FH. Increases in CSF $\left[\mathrm{Na}^{+}\right]$precede the increases in blood pressure in Dahl S rats and SHR on a high-salt diet. Am J Physiol Heart Circ Physiol. 2004; 287:H1160H1166. [PubMed: 15130889]

Huang BS, Wang H, Leenen FH. Chronic central infusion of aldosterone leads to sympathetic hyperreactivity and hypertension in Dahl S but not Dahl R rats. Am J Physiol Heart Circ Physiol. 2005; 288:H517-H524. [PubMed: 15458950]

Huang BS, White RA, Ahmad M, Jeng AY, Leenen FH. Central infusion of aldosterone synthase inhibitor prevents sympathetic hyperactivity and hypertension by central $\mathrm{Na}^{+}$in Wistar rats. Am J Physiol Regul Integr Comp Physiol. 2008; 295:R166-R172. [PubMed: 18495825]

Huang BS, White RA, Ahmad M, Tan J, Jeng AY, Leenen FH. Central infusion of aldosterone synthase inhibitor attenuates left ventricular dysfunction and remodelling in rats after myocardial infarction. Cardiovasc Res. 2009a; 81:574-581. [PubMed: 18689429]

Huang BS, White RA, Jeng AY, Leenen FH. Role of central nervous system aldosterone synthase and mineralocorticoid receptors in salt-induced hypertension in Dahl salt-sensitive rats. Am J Physiol Regul Integr Comp Physiol. 2009b; 296:R994-R1000. [PubMed: 19118098]

Janiak P, Brody MJ. Central interactions between aldosterone and vasopressin on cardiovascular system. Am J Physiol Regul Integr Comp Physiol. 1988; 255:R166-R173.

Janiak PC, Lewis SJ, Brody MJ. Role of central mineralocorticoid binding sites in development of hypertension. Am J Physiol Regul Integr Comp Physiol. 1990; 259:R1025-R1034.

Lassman MN, Mulrow PJ. Deficiency of deoxycorticosterone-binding protein in the hypothalamus of rats resistant to deoxycorticosterone induced hypertension. Endocrinology. 1974; 94:1541-1546. [PubMed: 4831119]

Lloyd-MacGilp SA, Torielli L, Bechtel S, Tripodi G, Gomez-Sanchez CE, Zagato L, Bernhardt R, Kenyon CJ. Mutations in aldosterone synthase gene of Milan hypertensive rats: phenotypic consequences. Am J Physiol Endocrinol Metab. 2002; 282:E608-E617. [PubMed: 11832364]

London GM, Safar ME, Weiss YA, Corvol PL, Menard JE, Simon AC, Milliez PL. Relationship of plasma renin activity and aldosterone levels with hemodynamic functions in essential hypertension. Arch Intern Med. 1977; 137:1042-1047. [PubMed: 327963]

MacKenzie SM, Clark CJ, Fraser R, Gomez-Sanchez CE, Connell JMC, Davies E. Expression of 11 $\beta$ hydroxylase and aldosterone synthase genes in rat brain. J Mol Endocrinol. 2000; 24:321-328. [PubMed: 10828825] 
MacKenzie SM, Lai M, Clark CJ, Fraser R, Gomez-Sanchez CE, Seckl JR, Connell JM, Davies E. $11 \beta$-Hydroxylase and aldosterone synthase expression in fetal rat hippocampal neurons. J Mol Endocrinol. 2002; 29:319-325. [PubMed: 12459034]

Mark AL. Sympathetic neural contribution to salt-induced hypertension in Dahl rats. [Review]. Hypertension. 1991; 17:I86-I90. [PubMed: 1987017]

Mellon SH. Neurosteroids: biochemistry, modes of action and clinical relevance. J Clin Endocrinol Metab. 1994; 78:1003-1008. [PubMed: 8175951]

Pacha J, Pohlova I. The influence of high salt intake on intestinal Na, K-ATPase in Wistar and Dahl rats. Acta Physiol Scand. 1993; 148:69-75. [PubMed: 8392776]

Pitt B. Effect of aldosterone blockade in patients with systolic left ventricular dysfunction: implications of the RALES and EPHESUS studies. Mol Cell Endocrinol. 2004; 217:53-58. [PubMed: 15134801]

Rapp JP, Tan SY, Margolius HS. Plasma mineralocorticoids, plasma renin, and urinary kallikrein in salt-sensitive and salt-resistant rats. Endocr Res Commun. 1978; 5:35-41. [PubMed: 710365]

Reul JMH, De Kloet ER. Two receptor systems for corticosterone in rat brain: microdistribution and differential occupation. Endocrinology. 1985; 117:2505-2511. [PubMed: 2998738]

Roland BL, Funder JW. Localization of $11 \beta$-hydroxysteroid dehydrogenase type 2 in rat tissues: in situ studies. Endocrinology. 1996; 137:1123-1128. [PubMed: 8603583]

Seckl JR, Walker BR. Minireview: 11 $\beta$-hydroxysteroid dehydrogenase type 1- a tissue-specific amplifier of glucocorticoid action. Endocrinology. 2001; 142:1371-1376. [PubMed: 11250914]

Stewart PM, Wallace AM, Valentino R, Burt D, Shackleton CHL, Edwards CRW. Mineralocorticoid activity of liquorice: 11- $\beta$-hydroxysteroid dehydrogenase deficiency comes of age. Lancet. 1987; ii:821-824. [PubMed: 2889032]

Stromstedt M, Waterman MR. Messenger RNAs encoding steroidogenic enzymes are expressed in rodent brain. Brain Res Mol Brain Res. 1995; 34:75-88. [PubMed: 8750863]

Takata Y, Yamashita Y, Takishita S, Fujishima M. Lack of increase in sodium concentration of cerebrospinal fluid in DOCA-salt hypertensive rats. Am J Hypertens. 1988; 1:45S-48S. [PubMed: 3415808]

Takeshita A, Mark AL, Brody MJ. Prevention of salt-induced hypertension in Dahl strain by 6hydroxydopamine. Am J Physiol Heart Circ Physiol. 1979; 236:H48-H52.

Tomlinson JW, Walker EA, Bujalska IJ, Draper N, Lavery GG, Cooper MS, Hewison M, Stewart PM. $11 \beta$-Hydroxysteroid dehydrogenase type 1: a tissue-specific regulator of glucocorticoid response. Endocr Rev. 2004; 25:831-866. [PubMed: 15466942]

Tsutamoto T, Wada A, Maeda K, Hayashi M, Tsutsui T, Ohnishi M, Fujii M, Matsumoto T, Yamamoto T, Takayama T, Ishii C. Transcardiac gradient of aldosterone before and after spironolactone in patients with congestive heart failure. J Cardiovasc Pharmacol. 2003; 41:S19S22. [PubMed: 12688391]

Tsutamoto T, Wada A, Maeda K, Mabuchi N, Hayashi M, Tsutsui T, Ohnishi M, Sawaki M, Fujii M, Matsumoto T, Horie H, Sugimoto Y, Kinoshita M. Spironolactone inhibits the transcardiac extraction of aldosterone in patients with congestive heart failure. J Am Coll Cardiol. 2000; 36:838-844. [PubMed: 10987608]

Wright I, Upton N, Marsden C. Effect of established and putative anxiolytics on extracellular 5-HT and 5-HIAA in the ventral hippocampus of rats during behavior on the elevated X-maze. Psychopharmacology. 1992; 109:338-346. [PubMed: 1285416]

Ye P, Nakamura Y, Lalli E, Rainey WE. Differential effects of high and low steroidogenic factor-1 expression on $C Y P 11 B 2$ expression and aldosterone production in adrenocortical cells. Endocrinology. 2009; 150:1303-1309. [PubMed: 18974272]

Yu L, Romero DG, Gomez-Sanchez CE, Gomez-Sanchez EP. Steroidogenic enzyme gene expression in the human brain. Mol Cell Endocrinol. 2002; 190:9-17. [PubMed: 11997174]

Yu Y, Wei SG, Zhang ZH, Gomez-Sanchez E, Weiss RM, Felder RB. Does aldosterone upregulate the brain renin-angiotensin system in rats with heart failure? Hypertension. 2008; 51:727-733. [PubMed: 18227408] 

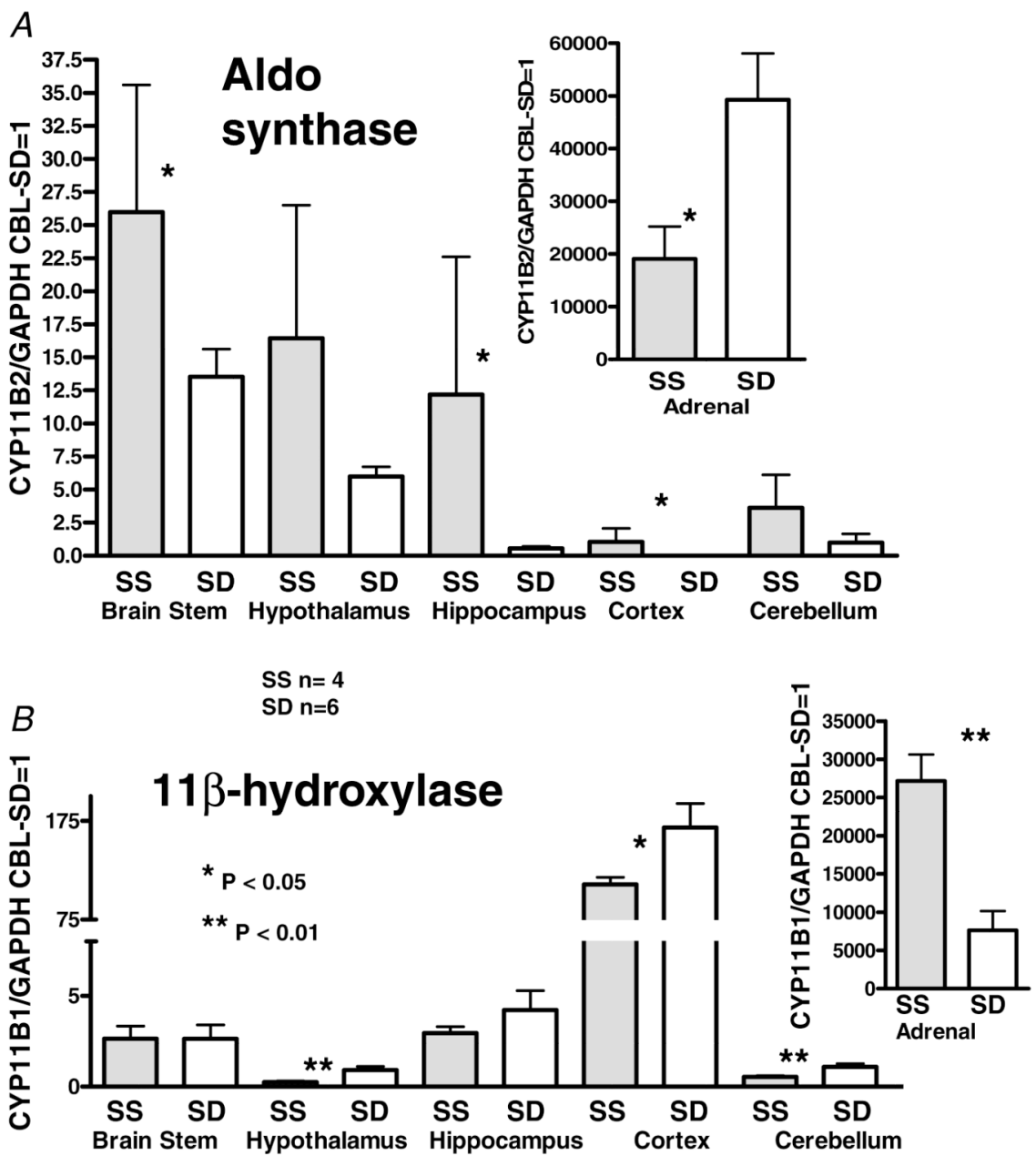

Figure 1. Real-time RT-PCR measurement of mRNA for the CYP11B2 and CYP11B1 genes that code for aldosterone synthase and the $11 \beta$-hydroxylase enzymes, respectively, in different parts of the brain and in the adrenal gland

The results are expressed as multiples of the mRNA/GAPDH of the cerebellum of the SD rats assigned the value of 1 . Bars indicate s.E.M.; $* P<0.05$, $* * P<0.01$. 


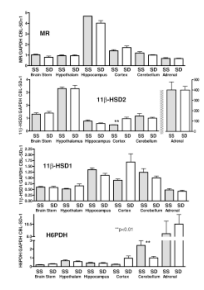

Figure 2. Real-time RT-PCR measurement of mRNA for the genes coding for the

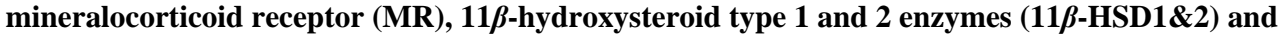
hexose-6-phosphate dehydrogenase enzyme (H6PDH) in different parts of the brain and in the adrenal

The results are expressed as multiples of the mRNA/GAPDH of the cerebellum of the SD rat assigned the value of 1 . Bars indicate s.E.M. 

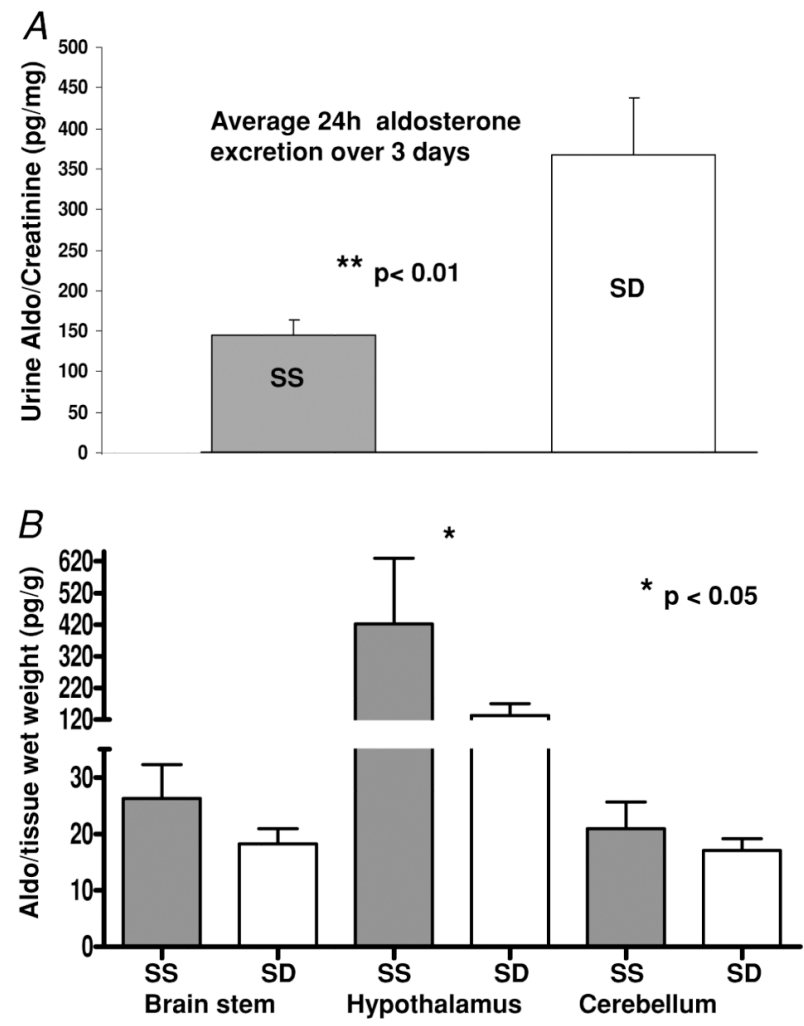

Figure 3. Average total aldosterone production and content in brain $A$, average $24 \mathrm{~h}$ urine excretion of the 9 pairs of SS and 8 pairs of SD rats collected over 3 consecutive days (ratio of pg aldo (mg creatinine $\left.)^{-1}(24 \mathrm{~h})^{-1}\right) . B$, aldosterone concentration (expressed as pg ( $\mathrm{g}$ wet tissue weight $)^{-1}$ ) in brainstem, hypothalamus and cerebellum of SS and SD rats. Tissues were pooled from 3 animals; $n=8$. Bars indicate s.е.; $* P<0.05$, $* * P<$ 0.01 . 


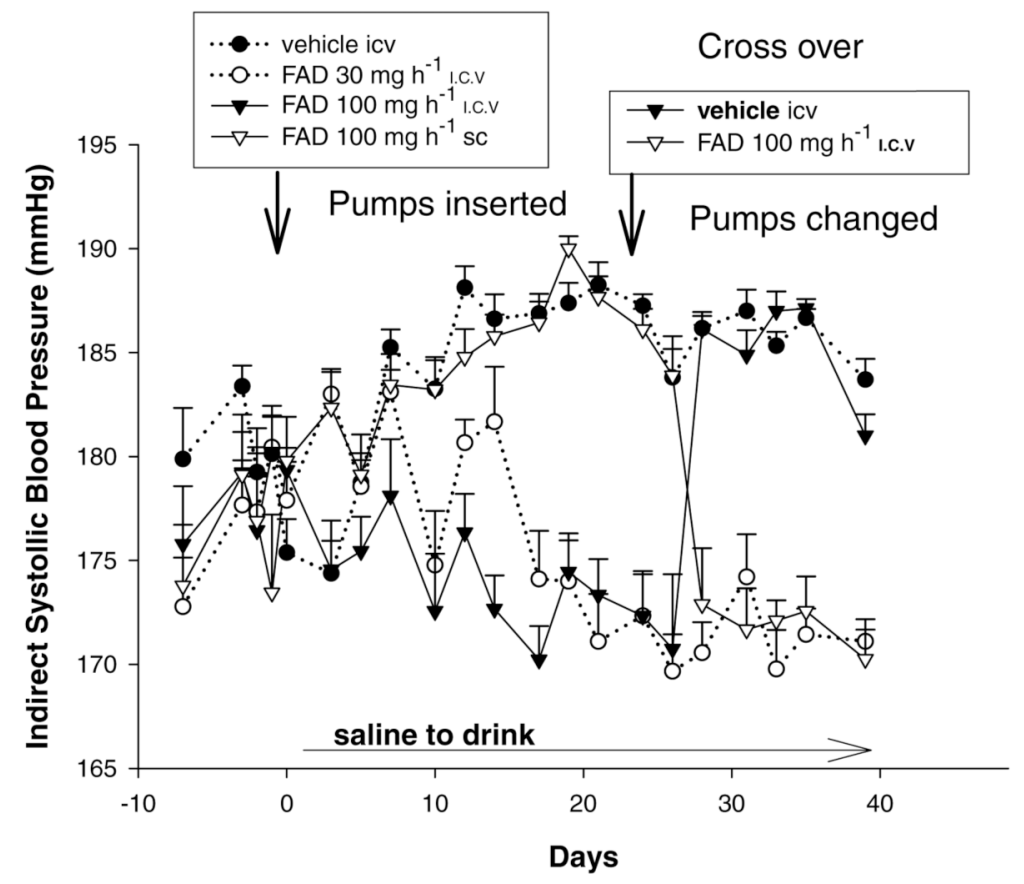

Figure 4. Results of a cross-over blood pressure study in SS rats with established hypertension challenged with a high-salt diet

Systolic blood pressure was measured in unheated trained rats twice a week by tail-cuff plethysmography. The i.c.v. infusions of vehicle or FAD286 were interchanged between groups 3 and 4 after 22 days. Bars indicate s...m. For simplicity, statistical differences are discussed in the text. 